\title{
Erratum to: Pazopanib in advanced renal cell carcinoma: a guide to its use in the EU
}

\author{
Katherine A. Lyseng-Williamson ${ }^{1}$
}

Published online: 9 November 2015

(c) Springer International Publishing Switzerland 2015

\section{Erratum to: Drugs Ther Perspect (2015) 31:372-377 DOI 10.1007/s40267-015-0249-2}

The author has alerted us to the following error:

Page 376, section "Compared with sunitinib", column 2, lines $18-26$.

The paragraph that previously read:

'Dose reductions were required in 44 and $51 \%$ of pazopanib and placebo recipients, respectively, and 44 and $49 \%$ of patients in the respective groups required treatment interruption for $\geq 7$ days (44 and $49 \%$ ) [10]. In the pazopanib group, $24 \%$ of patients prematurely discontinued therapy because of adverse events compared with $20 \%$ in the placebo group; this BGD was primarily due to the proportion of patients in each group who discontinued therapy because of liver-related events (6 vs. $1 \%)$ [10].' should read:

'Dose reductions were required in 44 and $51 \%$ of pazopanib and sunitinib recipients, respectively, and 44 and $49 \%$ of patients in the respective groups required treatment interruption for $\geq 7$ days (44 and $49 \%$ ) [10]. In the pazopanib group, $24 \%$ of patients prematurely discontinued therapy because of adverse events compared with $20 \%$ in the sunitinib group; this BGD was primarily due to the proportion of patients in each group who discontinued therapy because of liver-related events (6 vs. $1 \%$ ) [10].'

The online version of the original article can be found under doi: 10.1007/s40267-015-0249-2.

Katherine A. Lyseng-Williamson

dtp@adis.com

1 Springer, Private Bag 65901, Mairangi Bay, 0754 Auckland, New Zealand 